Brit. J. vener. Dis. (1964), 40, 1.

\title{
EDITORIAL
}

\section{INFECTION OF THE EYE AND THE GENITAL TRACT BY TRIC AGENT}

On page 3 of this issue Prof. Barrie R. Jones of the Institute of Ophthalmology, London, describes the features of infection of the eye by TRIC agent (Bedsonia) and suggests that investigation, using methods now available, may prove that this agent is an important cause of "non-specific" genital infection.

Interest in this problem goes back many years; in fact it was the description of the gonococcus in 1879 by Albert Neisser which started an intensive bacteriological study of conjunctivitis occurring in the newborn baby. This led to the recognition of a non-gonococcal form of the disease. Following the parallel of gonorrhoea, it seemed reasonable to suppose then, as was suggested eighty years ago by Kroner (1884), that such cases were due to an infectious agent in the birth-canal of the mother.

A major step forward was taken when Halberstaedter and Prowazek (1907) described the structures now known as Halberstaedter-Prowazek inclusion bodies in the cytoplasm of conjunctival epithelial cells from patients suffering from trachoma. Shortly after this, similar inclusions were found in conjunctival epithelial cells obtained from babies suffering from amicrobial ophthalmia neonatorum, in urethral material from men suffering from nongonococcal urethritis, and in material obtained from the genito-urinary tracts in the cases of the parents of babies suffering from ophthalmia neonatorum. Material from each of these sources was found to produce conjunctivitis in the experimental animal.

For nearly half a century, further advances in knowledge in this field were hampered by the fact that all attempts to isolate the causal organism proved unsuccessful. However, T'ang, Chang, Huang, and Wang (1957) isolated virus from patients suffering from trachoma by inoculating conjunctival material into the embryonate yolk-sacs of eggs. A similar agent was then isolated from the conjunctiva of a newborn baby affected by inclusion blennorrhoea and from the cervix of the mother of another baby suffering from that disease (Jones, Collier, and Smith, 1959).

The successful method for growing the agent has been applied to the eye and to the genital tract in a collaborative study by Prof. Barrie R. Jones and Dr. Khalaf Al-Hussaini of the Institute of Ophthalmology, London, and Dr. Eric M. C. Dunlop of the Whitechapel Clinic of The London Hospital. They studied in detail the association of genital infection with eye disease due to this agent and their results are reported in this issue (pages 19-42). They found inclusions in scrapings from the conjunctiva in the cases of five babies suffering from ophthalmia neonatorum, and isolated virus from that site in the case of three. They found inclusions in scrapings from the cervix of one of the mothers and isolated virus from that site. Four of the five fathers were examined and were found to have urethritis. Scrapings were taken from the urethra in three cases; the urethritis was abacterial, inclusions were present in all three cases, and virus was isolated in one. This is the first report of the isolation of virus from the urethra of the father of a baby suffering from ophthalmia neonatorum. More important is the fact that it is the first report of the definite isolation of a virus from what would otherwise have been called "non-specific" urethritis.

These authors have also produced evidence suggesting that genital infection by TRIC agent occurs in association with trachoma, and with other forms of infection of the eye by this agent occurring in the adult. This association has long been suspected.

Further work will eventually define the place of this agent as a cause of disease. In addition it will affect our concept of lymphogranuloma venereum, which is due to a related agent; for it seems that TRIC agent also may cause proctitis and a positive complement-fixation test for lymphogranuloma venereum.

We are reminded that, since the time of Pasteur, a diagnosis limited to an anatomical statement of the structures attacked by an infectious process is insufficient: to be complete the diagnosis must include the name of the causal organism. This important collaborative study affords just such a precise diagnosis for a section of non-gonococcal genital infections. How big this section will prove to be only further study can reveal.

\section{REFERENCES}

Halberstaedter, L., and Prowazek, S. von (1907). Dtsch. med. Wschr., 33, 1285.

Jones, B. R., Collier, L. H., and Smith, C. H. (1959). Lancet, 1, 902.

Kroner, T. (1884). Zbl. Gynäk., 8, 643.

Neisser, A. (1879). Zbl. med. Wiss., 17, 497.

T'ang, F. F., Chang, H. L., Huang, Y. T., and Wang, K. C. (1957). Chin. med. J., 75, 429. 